\title{
Injuries among older adults: the challenge of optimizing safety and minimizing unintended consequences
}

\section{S Binder}

Injury Prevention 2002;8(Suppl IV):iv2-iv4

See end of article for author's affiliation

........

Correspondence to: Dr S Binder, National Center for Injury Prevention and Control, Centers for Disease Control and Prevention (CDC), K-02, 4770 Buford Highway, NE, Atlanta, GA 30341 USA; scb1@cdc.gov

\begin{abstract}
Objectives: To describe the problem of falls, motor vehicle related injuries, and suicide among older adults, and issues related to their prevention.

Methods: Summary and synthesis of selected literature.

Results: About 39000 adults aged 65 and older die each year in the United States from injuries; worldwide this annual toll is about 946000 persons. The top three causes of injury related death in this age goup in the United State are falls, those related to motor vehicle crashes, and suicide. Effective strategies exist for preventing fall related injuries and deaths. Preventing injuries and deaths from motor vehicles and suicide may be more difficult because of the nature of these problems.

Conclusions: As the number and percentage of older adults continues to rise in the United States and globally, new approaches to preventing injuries will be critical. Interventions will need to operate at multiple levels - directed at the individual, at interpersonal relationships, and at the community level.
\end{abstract}

A though injuries are the leading cause of death in the United States for people in the first four decades of life, rates of injury death for those 70 and older are the highest of almost all age groups. In the United States, around 39000 adults older than 65 years died from injuries in 1999. ${ }^{1}$ The leading injury causes of death among older adults in the United States are falls, motor vehicle crashes, and suicide.

\section{FALLS, MOTOR VEHICLE RELATED INJURIES, AND SUICIDE AMONG OLDER ADULTS IN THE UNITED STATES \\ Falls}

Each year, unintentional falls kill over 10000 adults age 65 and older in the United States. ${ }^{1}$ However, deaths are the most extreme manifestation of a much larger injury problem. For example, one of the most devastating nonfatal impacts of a fall can be a hip fracture. Over 330000 older adults were hospitalized for hip fractures in 1999, most of whom were women. ${ }^{2}$ Of those hip fracture patients who survive, many experience decreases in their mobility or their ability to function independently. ${ }^{3}$ A recently published study among women 75 years and older found that $80 \%$ would rather be dead than experience the loss of independence and quality of life from a bad hip fracture and admission to a nursing home. ${ }^{4}$ In 1994, falls among older adults cost over \$20 billion. ${ }^{5}$ Falls are mentioned as a contributing factor in $40 \%$ of nursing home admissions in the United States. ${ }^{6}$

For those who are not left permanently disabled by a fall, residual fear of falling and loss of confidence often means a "change to a quiet life" and dramatically decreased activities-which may be effective in reducing injury risk in some cases, but may have the paradoxic effect of increasing risk factors for falls and other injuries. ${ }^{7}$

Many risk factors for falls and fall injuries have been identified. Examples of these include muscle weakness, gait deficits, balance problems, and visual impairment. ${ }^{8}$ Use of certain medications, especially use of multiple medications simultaneously and use of psychotropic drugs, increases fall risk. ${ }^{89}$ Environmental factors, such as obstacles (especially in dark rooms) and footwear that resists pivoting, may also contribute to risk. ${ }^{10}$ An important risk factor is a previous fall; those who stumble repeatedly or fall are severalfold more likely to fall again in the next year. ${ }^{11}$ It is likely that there is interaction and synergy among risk factors, such that the risk of falling increases dramatically as the number of risk factors increases. ${ }^{8}$

\section{Motor vehicle related injuries}

In 1999, 7500 persons ages 65 years and older were killed in motor vehicle crashes in the United States. ${ }^{1}$ Older drivers are killed out of proportion to their level of exposure. In the United States in 1999, drivers aged 65 years or older made up $14.4 \%$ of licensed drivers, ${ }^{12}$ but accounted for $16.8 \%$ of deaths to drivers. ${ }^{13}$ This is particularly striking because older drivers drive less than younger ones. Calculated on the basis of estimated annual miles driven, death rates for drivers 85 years and older are nine times higher than those for drivers 25 to 69 years old..$^{14}$

Risk factors for car crashes and injuries among older drivers include those related to the individual, the vehicle, and the road. Visual disorders are believed to be an important cause of driving problems; however, the link between decreased visual acuity (the most commonly tested aspect of vision), and increased risk of crashes and injuries is present but not very strong. Thus, conventional vision tests may not be assessing those characteristics most important to safer driving. Cognitive impairment, especially related to dementia, is associated with higher motor vehicle crash rates in older individuals. Frailty of older adults contributes to higher death rates when older adults are involved in motor vehicle crashes. ${ }^{15}$

Many older persons get killed as pedestrians. Death rates of pedestrians begin to increase sharply at age 65 in the United States. Whereas around $85 \%$ of motor vehicle fatalities among adults 70 years and older in the United States occur to drivers or motor vehicle passengers, ${ }^{16}$ in many other countries, such as the United Kingdom and Norway, deaths are more evenly split between motor vehicle occupants and pedestrians. ${ }^{17}$

\section{Suicide}

For all ages considered together, suicide is the eleventh leading cause of death in the United States. Rates increase with age, and are highest among Americans age 65 and older. In 1999, more than 5500 people age 65 and older killed themselves in the United States, with older men being at particular risk. ${ }^{1}$ Firearms are the most commonly used means of suicide. ${ }^{18}$ Risk 
factors for suicide in this age group include psychiatric illnesses, including depression; social circumstances; and physical illnesses. However, the relation of these risk factors to suicidal behavior is complex. ${ }^{19}$

\section{INTERVENTIONS FOR PREVENTING FALLS, MOTOR VEHICLE RELATED INJURIES, AND SUICIDE AMONG OLDER ADULTS \\ Falls}

Multifaceted programs, including exercise, vision correction, medication review and adjustment, and environmental modification, appear to be effective in randomized control trials. Individually prescribed programs of muscle strengthening and balance retraining, and also Tai Chi (which combines strength and balance training) may be effective as sole interventions for preventing falls. ${ }^{20}$ Devices such as hip protectors, which work by reducing the amount of energy absorbed by the bone during a fall onto the hip, appear to be efficacious among frail older adults, with a recent trial showing a $60 \%$ reduction in hip fractures among those randomized to receive the device. ${ }^{21}$

\section{Motor vehicle related injuries}

For preventing motor vehicle crashes and injuries among older adults, a variety of approaches have been suggested, including changes in car design (for example, to make it easier to drive and to provide better protection in the event of a crash), changes in roadways (for example, clearer signs), and safer pedestrian walkways (for example, pedestrian islands and longer walk signals). Further evaluation is needed of interventions such as driver training and reverse graduated licences (that is, license restrictions applied gradually as adults age or lose capability). Research to devise tools for determining when a person should stop driving has to date not yielded an approach that adequately identifies those at high risk for crashes while ensuring that those who can still drive safely are allowed to do so. As nearly $90 \%$ of trips by older persons are made in automobiles, ${ }^{22}$ taking away somebody's license can have the adverse consequence of reducing mobility and independence.

\section{Suicide}

Rigorous research on the effectiveness of suicide prevention programs has been limited in all age groups, including older adults. Much of the research has focused on recognition and treatment of mental disorders. With the possible exception of the use of lithium for manic depressive illness, the limited numbers of studies to date have not provided much evidence that medical therapy or psychotherapeutic approaches towards depression reduce suicide risk. ${ }^{23-25}$ Given the importance of suicide as a public health problem, finding what works to prevent suicide is critical.

Suicide also provides an example of how taking action to prevent one form of injury may impact another. For example, use of medications to treat psychiatric disorders that are risk factors for suicide may increase risk for falls and may also impact motor vehicle crash risk.

\section{INTERNATIONAL PERSPECTIVES ON INJURIES AMONG OLDER ADULTS}

Worldwide, injuries are an important cause of death among older adults, resulting in 946000 deaths annually among adults aged 60 years and older. ${ }^{26}$ The importance of different causes of injury varies by region; war injuries are among the top 15 causes of death for older adults in the Eastern Mediterranean region, self inflicted injuries and falls in low and middle income Europe and the western Pacific/China region, and road traffic injuries in South East Asia and India. Globally, self inflicted injuries are the fifteenth leading cause of death for people aged 60 and older. ${ }^{27}$

Ideally, all countries should participate in international efforts to share data and explore solutions to injury problems.
United States participation in such efforts is critical for several reasons. One important reason is the need to reduce risks to US workers and travelers abroad from motor vehicle crashes and violence. Although most health related travel advice for US travelers going overseas focuses on infectious diseases, the leading cause of death in US travelers overseas is cardiovascular $(49 \%)$, followed by injuries $(25 \%){ }^{28}$ Among younger travelers, such as Peace Corps volunteers, injuries are the leading cause of death. ${ }^{29}$ Other reasons to participate in multinational injury prevention and control efforts include the economic impact of injuries on US interests, opportunities to better understand injury issues and injury prevention, and the obligation to contribute to global public health.

Although approaches to injury prevention need to be tailored for local problems and circumstances, some experiences are transferable from one country to another. For example, the excellent research on falls and fall prevention in older adults conducted in Australia ${ }^{7}$ has applicability to the United States, as does the experience with efforts to reduce pedestrian fatalities in Europe. ${ }^{17}$ The promulgation of national suicide prevention strategies in Finland and other nations provided an approach that could be adopted by the United States; following in the footsteps of other nations, the United States published its Call to Action to Prevent Suicide in 1999 and its National Strategy for Suicide Prevention in 2001. ${ }^{30}$

\section{WICKED PROBLEMS}

In contrast to falls prevention, for which some effective interventions have been shown, developing proven effective interventions for reducing suicide and motor vehicle deaths among older adults has been more difficult. This is partly because of the nature of the problems and partly because of the nature of the potential solutions. Such problems, like many addressed by public health, meet the definition of "wicked problems", with the term wicked being used to mean "tricky". ${ }^{31}$

Unlike tame problems, which are relatively easily defined and have straightforward answers, wicked problems result from sets of interlocking issues. Even describing the wicked problem is difficult; a key issue is what level of abstraction is the appropriate one to use. Therefore, solving these problems requires multiple, complex, and dynamic approaches. There are no right or wrong solutions to wicked problems, only better or worse ones. ${ }^{31}$

Suicide in older adults is an example of a wicked problem. Whether one frames this public health issue as one that is a result of individual risk factors (for example, mental illness), risk factors related to interpersonal relationships, or societal issues determines the kinds of interventions which are most important to evaluate. For example, studies of suicide prevention have largely focused on clinical interventions, such as early diagnosis and treatment of depression; however, this approach has not been clearly shown to be effective. ${ }^{23-25}$ The strong influence of societal factors is suggested by differences in demographic patterns of suicide in different countries. For example, in the United States, suicide rates among women do not change much with age, whereas in China they follow the same pattern as those of men, increasing with age. ${ }^{132}$ This suggests that solution of the problem of suicide will require interventions at multiple levels, and may lie in addressing complex issues, for example, related to interpersonal relationships and the role of older people in society.

Motor vehicle related injuries among older adults is another wicked problem. Some of the risk factors lie with the adults themselves and may be amenable to fixing with interventions like eyeglasses and cataract surgery. However, much of the problem may be our built environment and will require communities to choose to invest in structural changes to increase the safety of motor vehicle occupant and pedestrian safety.

How does one solve a wicked problem? First, whatever can be tamed, should be. Randomized controlled trials of 
interventions to reduce suicide among mildly depressed older adults and biomechanics studies to find out how to protect frail bodies in cars are examples of approaches to taming portions of the related wicked problem.

Second, we must accept that interventions to solve wicked problems need to operate at multiple levels: directed at the individual-for example, vision correction; at interpersonal relationships; and at the community level-for example, the built environment.

Finally, solutions to wicked problems require new partners and new ways of thinking - for example, working to ensure that alternative transportation is available for older adults to remove barriers for those drivers who should give up their car keys, and working with movements to increase livability in our cities.

\section{WHY IT IS IMPERATIVE TO START NOW TO PREVENT INJURIES AMONG OLDER ADULTS}

The attitudes and behaviors of those who are aging now and in the future may be changing in ways that increase injury risks for older adults. For example, a study from Australia ${ }^{7}$ concluded that many older people do not identify themselves as being "old" and therefore do not acknowledge their risk of falls. An increasing emphasis on maintaining the lifestyle formerly associated with younger people is illustrated by the large increases in the annual number of miles driven by older adults from 1990 to $1995 .{ }^{33}$ Older drivers are the most rapidly growing segment of the driving population in the United States, both in terms of numbers of drivers and also numbers of miles driven annually per driver. As a result of the aging of the population and the emphasis on staying mobile, it is estimated that by 2030 , one out of every four persons eligible to drive will be 65 or older, and drivers aged 65 and older will account for $25 \%$ of drivers involved in crashes with fatalities, compared with $14 \%$ in $1999 .{ }^{34}$

Furthermore, the population of older adults is growing rapidly. In April 2002, the United Nations issued World Population Ageing: 1950-2020, which noted that older adults are the fastest growing population segment worldwide, growing at a rate of $2 \%$ per year. ${ }^{35}$ By 2050 , the world will have more than 2 billion people age 60 and over. For the first time in the history of mankind, there will be more people aged 60 and older than the number of people younger than 15. For both developing and developed nations, planning for the aging of the population is critical.

Injuries among older adults are a significant and increasing problem. Given the rapid increase in numbers of older adults, it is imperative to invest now to understand how to prevent injuries and to plan for social and environmental changes that will decrease injuries among older persons. Interventions to prevent falls among older adults have been shown to be effective and should be more widely adopted. For prevention of wicked problems such as suicide and car crashes, interventions are more difficult but just as essential.

\section{Author's affiliation}

S Binder, National Center for Injury Prevention and Control, Centers for Disease Control and Prevention (CDC), Atlanta, Georgia, USA

\section{REFERENCES}

1 Centers for Disease Control and Prevention. WISQARS injury mortality reports. Online database. Atlanta, GA: National Center for Injury Prevention and Control, Centers for Disease Control and Prevention (retrieved May 22, 2002 from http://webapp.cdc.gov/sasweb/ncipc/ mortrate 10. html)

2 Stevens J. Falls among older adults: moving from research to practice. Presented at the World Injury Conference, Montreal, Quebec, Canada. May 13, 2002

3 Magaziner J, Hawkes W, Hebel JR, et al. Recovery from hip fracture in eight areas of function. J Gerentol 2000;9:M498-507.

4 Salkeld G, Cameron ID, Cumming RG, et al. Quality of life related to fear of falling and hip fracture in older women: a time trade off study. BM 2000;320:241-6.
5 Englander F, Hodson TJ, Terregrossa RA. Economic dimensions of slip and fall injuries. J Forensic Sci 1996;41:733-46.

6 Tinetti ME, Speechley M, Ginter SF. Risk factors for falls among elderly persons living in the community. N Engl J Med 1988;319:1701-8.

7 Commonwealth of Australia. Australia Department of Health and Ageing. National falls prevention for older people initiative "Step Out with Confidence". Publications approval number: 2848. 2001.

8 American Geriatric Society Panel, British Geriatric Society and American Academy of Orthopaedic Surgeons Panel on Falls Prevention. Guideline for the prevention of falls in older persons. J Am Geriatr Soc 2001;49:664-72

9 Leipzig RM, Cumming RG, Tinetti ME. Drugs and falls in older people: a systematic review and meta-analysis: I. Psychotropic drugs. J Am Geriatr Soc 1999:47:30-9.

10 Connell BR, Wolf SL, for the Atlanta FICSIT Group. Environmental and behavioral circumstances associated with falls at home among elderly individuals. Arch Phys Med Rehabil 1997;78:179-86.

11 Teno J, Kiel DP, Mor V. Multiple stumbles: a risk factor for falls in community-dwelling elderly. J Am Geriatr Soc 1990;38:1321-5.

12 Federal Highway Administration (FHA). Highway statistics 1999. Office of Highway Policy Information. Publication No. FHWA-PL-00-020 Washington, DC: FHA, October 2000

13 National Highway Traffic Safety Administration (NHTSA). Traffic Safety Facts 1999: a compilation of motor vehicle crash data from the Fatality Analysis Reporting System and the General Estimates System. Retrieved July 21, 2002 from http://www-nrd.nhtsa.dot.gov/pdf/ nrd-30/NCSA/TSFAnn/TSF 1999.pdf

14 NHTSA. Traffic safety facts 1999: older population. Publication no. DOT HS 809 091. Washington, DC: NHTSA, December 2000.

15 Grabowski DC, Morrisey MA. The effect of state regulations on moto vehicle fatalities for younger and older drivers: a review and analysis. Milbank Q 2001;79:517-45.

16 NHTSA. Traffic safety facts 2000. A compilation of motor vehicle crash data from the Fatality Analysis Reporting System and the General Estimates System. Publication no. DOT HS 809 337. Washington, DC: NHTSA, 2002

17 Organisation for Economic Cooperation and Development (OECD). Ageing and transport. Mobility needs and safety issues. Paris: OECD Publications, 2001

18 Stevens JA, Hasbrouck LM, Durant TM, et al. Surveillance for injuries and violence among older adults. CDC Surveillance Summaries, December 17, 1999. MMWR 1999;48(SS-8):27-50.

19 Conwell Y. Suicide in later life: a review and recommendations for prevention. Suicide Life Threat Behav 2001:31 (suppl);32-47.

20 Gillespie LD, Gillespie WJ, Robertson MC, et al. Interventions for preventing falls in elderly people (Cochrane Review). In: The Cochrane Library, Issue 2. Oxford: Update Software, 2002.

21 Kannus $\mathbf{P}$, Parkkari J, Niemi S, et al. Prevention of hip fracture in elderly people with use of a hip protector. N Engl J Med 2000;343:1506-13.

22 US Federal Highway Administration. Nationwide personal transportation survey symposium: October 29-31, 1997, Bethesda Maryland. Washington, DC: Federal Highway Administration, US Department of Transportation, 1999.

23 Verkes RJ, Cowen PJ. Pharmacotherapy of suicidal ideation and behaviour. In: Hawton K, van Heeringen K, eds. Suicide and attempted suicide. Chichester, UK: John Wiley and Sons, 2000:487-502.

24 Heard HL. Psychotherapeutic approaches to suicidal ideation and behaviour.In: Hawton K, van Heeringen K, eds. Suicide and attempted suicide. Chichester, UK: John Wiley and Sons, 2000:503-18.

25 Khan A, Warner HA, Brown WA. Symptom reduction and suicide risk in patients treated with placebo in antidepressant clinical trials: an analysis of the Food and Drug Administration database. Arch Gen Psychiatry 2000;57:311-17.

26 World Health Organization (WHO). World Health Report 2001. Geneva: WHO (retrieved June 22, 2002 from http://www3.who.int/ whosis/

menu.cfm?path=evidence, burden, burden gbd2000,burden_gbd2000_regi on\&language=english)

27 Krug E, ed. Injury: a leading cause of the global burden of disease. Geneva: WHO, 1999

28 Hargarten SW, Baker TD, Guptill K. Overseas fatalities of United States citizen travelers: an analysis of deaths related to international travel. Ann Emerg Med 1991;20:622-6.

29 Hargarten SW, Baker SP. Fatalities in the Peace Corps, a retrospective study: 1962 through 1983. JAMA 1985;254:1326-9.

30 U.S. Department of Health and Human Services (HHS). National strategy for suicide prevention: goals and objectives for action. Washington, DC: HHS, 2001

31 Rittel HWJ, Webber MM. Dilemmas in a general theory of planning. Policy Sciences 1973:4;155-69

32 Phillips MR, Li X, Zhang Y, et al. Suicide rates in China, 1995-99. Lancet 2002;359:835-40.

33 Dellinger AM. Langlois JA, Li G. Fatal crashes among older drivers: decomposition of rates into contributing factors. Am J Epidemiol 2002; 155:234-41.

34 Lyman S, Ferguson SA, Braver ER, et al. Older driver involvements in police reported crashes and fatal crashes: trends and projections. Injury Prevention 2002;8:1 16-20

35 United Nations. World population ageing 1950-2050. Retrieved May 26, 2002 from http://www.un.org/esa/population/publications/ worldageing 19502050/Executivesummary_English.pdf. 